\title{
REWRITING GIRLHOOD. AMBIGUOUS BODIES IN CONTEMPORARY AMERICAN VISUAL ARTS: SALLY MANN'S AT TWELVE
}

\begin{abstract}
Drawing on cultural studies, gender theories, feminist theories, visual culture and semiotics, the present study investigates the subversive ways in which particular visual representations of teenage bodies introduce the generic transgression of cultural boundaries and limits in order to reflect the process of identity formation. Departing from various theories of corporeality and the semiotics of the body as a cultural entity, this study looks at contemporary American photographer Sally Mann's collection of photographs, At Twelve, in order to discern the visual mechanisms through which the staged representation of adolescent girls introduces the generous subversion of generic normative categories such as gender, age or social status. Furthermore, the present analysis suggests that trespassing boundaries is a necessary stage in the construction of self-sustainable identities in the aftermath of-postmodernism. Thus, the article tackles gender construction as a cultural edifice in which visual representation plays a significant part. Sally Mann's photography is eventually viewed as an instance of the contemporary interrogation of norms and boundaries of classical Western culture, as well as an innovative visual documenting of the transgressions, transitions and avoidance of limits that characterize adolescence.

Keywords: adolescence; identity; corporeality; representation; visual arts; American photography.
\end{abstract}

A quick look at the history of Western culture reveals an intense preoccupation with the human body, from visual representation to philosophical discourse. There is almost an obsession with corporeality, which can be traced back to ancient Greece and its glorification of perfect male bodies and which is

\footnotetext{
* Transilvania University of Braşov; Romania.
} 
well recognizable today in its contemporary allotropes: fitness, wellness, the beauty industry, plastic surgery. Set in sharp contrast to entities like the soul and the spirit by most ancient cultures, as the material, mortal and therefore inferior constituent of human identity, the body seems to have entered a new phase in the contemporary Western culture, with the transition from Homo Sapiens to Homo Deus. Drawing on Yuval Noah Harari already famous thesis that mankind has entered a new stage of evolution in which Man has replaced God(s) in various acts of creating life (Harari 5), it seems that the human body is now on its way to immortality or, at least, eternal youth. The recent innovations in medical engineering, genetics and technology entitle us to believe that mankind is on the verge of solving at least the problem of ageing, if not death.

Unlike other cultures, Western culture has entirely deleted death from human experience. This has had numerous consequences on the level of personal and collective identity, as it has fuelled intense anxieties, an entire collection of psychiatric disorders and a race to find eternal youth. Instead of looking at the process of ageing as a natural part of life, Western culture has gradually normalized it as a disease. The medicalization of getting old has, on the one hand, prolonged life expectancy, while on the other it has heavily marginalized and dispossessed the elderly. Institutionalizing the elderly has become common practice in most Western countries. Apparently performed to their service, it actually conceals an entire culture's fear of death and decay. Moreover, with the deletion of death from normal human experience, Western culture has in fact erased the very idea of limit from people's mindsets. With limits being blurred, concealed or utterly erased, the contemporary man seeks instant gratification, does not resist frustration and wants it all here and now. Within this frame of mind, the body's relevance becomes paramount. If historically, religion stigmatized the body as a site of sinful pleasures that had to be cleansed, controlled and disciplined through practices meant to mortify the body and redeem the soul in the hope for eternal afterlife, contemporary culture does the exact opposite: it glorifies the body as the here-and-now of all possible gratifications.

Perhaps the initiator of such a radical shift of perspective was Michel Foucault and his philosophical reconsiderations of the body as a site of culture. His theories according to which far from being the empty shell that contained an immortal soul, the body was in fact a locus of power and culture have reshaped Western thought and have dissolved the body and soul dyad. For Foucault, the 
body and power are inextricably linked, a statement that, by itself, rehabilitates the body from its inferior, mortal position. In this respect, in The Order of Things Foucault notes:

to man's experience a body has been given, a body which is his body - a fragment of ambiguous space, whose peculiar and irreducible spatiality is nevertheless articulated upon the space of things; to this same experience, desire is given as a primordial appetite on the basis of which all things assume value, and relative value; to this same experience, a language is given in the thread of which all the discourses of all times, all successions and all simultaneities may be given. This is to say that each of these positive forms in which man can learn that he is finite is given to him only against the background of its own finitude. (Foucault 314)

It is the purpose of the present study to show how the body is used to represent, subvert, signify and transgress boundaries and rewrite ideologies. More precisely, to investigate an instance of what Nicholas Mirzoeff defines in his 2005 study as the bodyscape:

The body in art must be distinguished from the flesh and blood it seeks to imitate. In representation the body appears not as itself, but as a sign. It cannot but represent both itself and a range of metaphorical meanings, which the artist cannot fully control, but only seeks to limit by the use of context, framing and style. This complex of signs is what I shall call the bodyscape. (Mirzoeff 2)

Also, this analysis seeks to demonstrate that the body's ambiguity that Foucault mentioned in The Order of Things can be meaningfully exploited by talented image and meaning creators. In this respect, Sally Mann's depiction of female adolescence is viewed as a challenge of canonical representations of the female body and identity, in a daring effort to discard the consecrated visual fetishism for the Madonna, the Whore and the domestic woman that Western culture employed in order to contain the Woman category. Moreover, this study seeks to explain that such representations of the female body that explore its visual transgressions can stand at the core of an intensely subversive challenge of binary logic, norms and categories. Focusing on girlhood as an essentially 
transient stage, a locus of infinite possibilities and directions for female identity, and rewriting it as a subversive inquiry into the nature of representation and categories is, without a doubt, the chief concern as well as merit of Mann's At Twelve. The main concern of this study is to unravel the ideological implications of representing the unrepresentable and analyze an innovative instance of identity in the making. Rewriting girlhood as essentially ambiguous and fluid and exiting the normative constraints of traditional representation is viewed as an important artistic reconfiguration of visual categories as well as an attack against Western culture's grand narratives.

\section{The ambiguous female body. A few considerations.}

The female body is perhaps one of the most intensely circulated cultural signifiers in the history of the Western world, both discursively and visually. Historically, despite the exclusion of women from the public sphere or perhaps precisely because of it, the female body has gradually become a place of fascination, mystification, cultural encoding and a source for numerous mythologies and narratives. Its intense allure was mainly the result of the fact that, in all cases, those representing and describing it were men.

Traditional Western culture rested on patriarchal ideology which definitely prioritized a masculine discourse and perspective. This led to the emergence of a well-defined, round-shaped, neatly bordered Woman category, exclusively externally defined, which left no room for women to represent or speak for themselves. The female body became thus a site of masculine colonization, a locus where masculine power was enforced and discourses inscribed. Representations of the female body were reduced to socially acceptable imagery or else, demonized. The Mother, the Virgin and the Whore, as standardized representations of women, are perhaps the best examples in this sense. But Western culture has also imagined the female monster, the freak, as a transgressive representational category bound to symbolically depict and sanction deviations from the Rule of the Father, the crossing of borders, the inbetween. A closer look at these iconic representations of women in classical Western culture reveals, however, a strongly ambivalent nature of the female body, capable of stirring both passion and horror, adoration and fear. In this respect, in Totem and Taboo, Freud explained that, under certain circumstances, the female body could become a locus of power, as well as a source of horror which generated power: 
The countless taboo regulations to which the women in savage communities are subject during menstruation are said to be due to a superstitious horror of blood, and this is no doubt in fact one of their determinants. But it would be wrong to overlook the possibility that in this case the horror of blood also serves esthetic and hygienic purposes, which are obliged in every case to cloak themselves behind magical motives. (Freud, Totem and Taboo 115)

Of course, Freud was talking from a strong patriarchal frame of mind which allowed him to conclude that female sexuality was a result of the (in)famous penis envy and therefore dependent on it:

anatomy has recognized the clitoris within the female pudenda as an organ homologous to the penis, and the physiology of sexual processes has been able to add that this little penis which no longer grows behaves in the childhood of the woman like a genuine and real penis, that it is the site of excitations which leads to its being touched, that its excitability gives the sexual activity of little girls a male character, and that it needs an effort of repression in the years of puberty to make the woman develop through discarding this male sexuality. (Freud, Collected Papers 67)

Patriarchal ideology was there at its best. Just like in the Biblical story of Adam and Eve, where Eve was created as an appendix of Man, from one of his ribs, and as mere entertainment for his solitude, female sexuality was explained as a consequence of a lack, a defect. Freud's phallocentric discourse was often attacked by feminist theories, as it reflected a binary hierarchy of the world, with man on top. Many feminist voices contested Freud's psychoanalytical theories on account of their allegiance to a narrow and intensely polarized vision of the world. In this respect, in Mothers, Monsters and Machines, Rosi Braidotti noted that

woman as a sign of difference is monstrous. If we define the monster as a bodily entity that is anomalous and deviant vis-à-vis the norm, then we can argue that the female body shares with the monster the privilege of bringing out a unique blend of fascination and horror. This logic of attraction and repulsion is extremely significant; psychoanalytic theory 
takes it as the fundamental structure of the mechanism of desire and, as such, of the constitution of the neurotic symptom: the spasm of the hysteric turns to nausea, displacing itself from its object. (Braidotti in Writing on the Body 65)

This horror resulted from both the physiogical promiscuity of the female sexual organs and the capacity of the female body to change shape and size in an unexpected way. This peculiarity of the female body and physiology has remained, for many centuries, a source of mystery and horror for men, who have tried to contain the terror by systematically controlling women through disciplinary and regulatory practices. Also, this also resulted in women's lack of visibility in the public sphere and their historical confinement within the domestic dimension.

Thus, the ambivalence of the female body became both a source for women's marginalization by the public eye, which remained traditionally male, and an underlying metaphor for women's more recent self-empowering promoted by various forms of feminism. Visually, this ambiguity is as disconcerting as it is unsettling. The female body presents itself as a riddle, an enigma which transgresses the rock-solid contours of classical patriarchal Reason, the one which made Descartes exclaim "I think, therefore I am".

The particular case of the teenage female body, which makes the subject of this paper, qualitatively supplements the aforementioned ambiguity. Not only does it pertain to a fluid corporeality that challenges the traditional propensity towards order and categorization, but it also introduces a subversion of that very corporeality, sabotaging thus twice the concepts of norm and normality. Through its symptomatic ambiguity and transgressive nature, the teenage female body renders binary logic inoperable and thus shatters the foundations of traditional Western thought. It becomes a visual trope for the contemporary assault on grand narratives, the unified body being just one of them. Rewriting the body becomes a central concern in contemporary visual arts, as an attempt to represent the "alarming instability" that mankind is currently facing. As Mirzoeff argues, "the modern period may be characterized in this regard as having an awareness that the body is mutable, incomplete and altogether human" (Mirzoeff 2).

\section{Sally Mann's Ambiguous Bodies: At Twelve}

The case of contemporary American photographer Sally Mann's At Twelve: 
Portraits of Young Women is the perfect opportunity to illustrate the subversive potential of the female body's visual ambiguity, for several reasons. First, because Mann is looking and then (re)presenting from a female stance, which is, I would say, much freer from patriarchal ideological constraints. Of course, not entirely free. Then, because the subjects she is looking at pertain to a very hardto-define category, if a category at all: teenagers. A category whose main trait is precisely the ambiguity which both patriarchy and radical feminism have systematically ignored in their halving of the world. Teenagers are essentially trapped in between, their essential feature resides in the fact that they are neither, nor, they are both existing and non-existent, both weak, marginal, lacking (reason, education, status, definition), as much as they are powerful, rebellious, young and, above all, eternal. In many ways, Mann's photographic essay is illustrative of what Nicholas Mirzoeff defines as the true crisis of the body, which, he argues, is "is as much in its representation and the understanding of that representation, as in its substance, providing the motive force behind a transformation of representation which can as yet only be imagined" (Mirzoeff 16).

At Twelve is Mann's collection of 37 black and white photos taken between 1983 and 1985 and published in 1988, featuring 12-year-old girls in apparently non-staged positions, while in familiar backgrounds. The girls were either Mann's own daughters or the daughters of close acquaintances and relatives living in her home state Virginia. Even though the photos appear to be snapshots, at the time of their publication there was a vivid controversy around whether or not they were staged, which would subvert their documentary value. At Twelve is a photographic essay meant to explore the ambiguous landscape of adolescence, that space located in between childhood and adulthood, but belonging to neither of them. The ambiguity of becoming is superseded by the ambiguity of the female body, which makes Mann's essay an exploration of boundaries and categories.

The first thing that catches the viewer's attention in these photos is not the image per se, not the contours, the bodies or the poses, but a general eerie atmosphere that is decidedly unsettling. I believe this is the result of a rather transgressive representation of the teenage girl, one that goes against social and cultural taboos, one that suggests, without stating, one that captures instances of becoming so well, that the spectator finds himself unable to operate with regular normative structures. Mann is brilliantly capturing not only images of becoming, 
but is also representing the teenage psyche, with its tensions, continuous rebellions and negotiations and, above all, with its utter glow of mortal immortality.

Mann's 12-year-olds are obviously re-enacting the Lolita stereotype, in a subversive gesture of transgressing the limits of a culture that puts both women and teenagers in marginal positions, deprives them of power and represents them through clichés. In many ways, Mann's adolescent bodies qualify as what Moira Gatens defined as imaginary bodies in her 1996 study dedicated to the semiotics of the female body:

An imaginary body is not simply a product of subjective imagination, fantasy or folklore. The term "imaginary" will be used in a loose but nevertheless technical sense to refer to those images, symbols, metaphors and representations which help construct various forms of subjectivity. (Gatens VIII)

Looking at Mann's photos, viewers are actively engaged in the construction of an imaginary of the female teenager that they need to map relying on the images they are presented with. Unjustly, photography has long been discarded as a mere imitation of reality, a faithful copy of the material world. With time, however, this misconception has changed, as the photographic image is so much more: it contains, at once, the artist's vision on a certain subject matter, a cultural context that needs to be acknowledged, as well as the viewer's own interpretation of what he sees. In the case of Sally Mann's photos, photography is actually discussing how teenage subjectivity is constructed through consciously and unconsciously entering social and cultural relations. Thus, physical bodies turn into imaginary bodies. This would be consistent with what Sally Robinson defines as the creation of female subjectivity,"the processes by which one becomes a woman are multiple and sometimes contradictory, and the category of "women" itself is, thus, a category marked by differences and instabilities" (Robinson 1).

Mann's teenage girls are both stable and unstable, their representations avoiding to resolve the inevitable disjuncture of the human body, contradicting thus Mirzoeff's claim that representations of the body are usually seeking to rectify the body's inherent transience (Mirzoeff 19). Most of them are depicted in carefully designed environments which are supposed to support as well as 
subvert the cultural narrative of the female identity. For instance, in one of the photos, untitled, we can see the 12-year-old possessively hugging her half-naked, monstrously pregnant mother, while gazing straight at the camera. The tension this image provokes is intense. There is a marked discrepancy between the yetto-come sexualization of the young girl's body, still lean, slender, curveless, almost childish, and the grotesque, yet natural deformity of her mother's pregnant body which leans against a disused mobile sink. The calamity of the landscape is merely suggested. The adult woman features in an imaginary of ruin and decomposition, disaffected and remote, her eyes closed and her head pulled back. By way of contrast, her teenage daughter emerges as a fresh, uncompromised promise of womanhood looking right into the camera. There is this knowledgeable gaze that she sends back to the viewer, as if to subversively undermine the ideological authority of the male gaze, a concept consecrated by Laura Mulvey in the 1970s. This teenage gaze resists objectification, consumption and corruption. It is straightfoward, intense, strong, as if to engage in a conflict with traditional representations of women. As Luce Irigaray points out in This Sex Which is Not One,

woman is traditionally a use-value for man, an exchange value among men; in other words, a commodity'[...] While her body finds itself thus eroticized, and called to a double movement of exhibition and chaste retreat in order to simulate the drives of the "subject", her sexual organ represents horror of nothing to see. (Irigaray 26-31)

In Candy Cigarette, Mann's own daughter looks back in an almost similar manner, while she poses holding a lit cigarette in her left hand. Mann's other daughter is with her back at the camera, looking away, down the road. Again, there is a sharp tension between the girl's childish body, her gaze and the cigarette, a subversive ambiguity in Mann's intention, as well as in the girl's look. The social role is merely sketched in the loose wrist that holds the cigarette and that does by no means fit a child. It the gesture of a child playing an adult, as they often do, a teenage girl posing as something she might become, yet she seems to resist. The cigarette girl faces the camera but has her back at the winding road which unfolds behind her. The other girl faces the road but resists the camera's devouring stare. Both are instances of becoming, unfolding possibilities, uncertainties, potentialities. Both are ambiguous, both resist cliché. 
There are infinite possible narratives underlining this image. As Mark Currie argues,

personal identity is not really contained in the body at all; it is structured by, or constituted by, difference. [...] identity is not within us because it exists only as narrative. By this I mean two things: that the only way to explain who we are is to tell our own story, to select key events which characterise us and organise them according to the formal principles of narrative to externalise ourselves as if talking of someone else, and for the purposes of self-representation; but also that we learn how to self-narrate from the outside, from other stories, and particularly through the process of identification with other characters. (Currie 17)

In Ianna and Doom, we see a beautiful girl lying on the hood of a dirty car on which a finger has spelled DOOM. The girl holds a butterfly net and stares right into the camera, although her head is resting on the car. Her body is fully dressed on top, but her legs are naked, exposed, somehow occupying the forefront of the photo. The cliché Mann is rewriting here is that of the teenage girl pictured in the front seat of her boyfriend's shiny car, pretty as a peach, happy and smiling, blissfully unaware of what lies ahead, both on the road and in life. Mann's Ianna seems doomed, the car is dirty and old, she is frowning, her body resists the cliché. The ambiguity of teenage surfaces again: caught between apparent bliss and doom, Mann's protagonist symbolically holds a butterfly net to represent her entrapment in-between.

In-betweenness is also at the core of Lisa and the Dog, a photo that focuses more on the ambiguous sexuality of the teenager, positioned this time in between her exhibitionist dog, playfully, yet fully exposing its private parts in the foreground, and an almost copulating couple, whose half-naked headless bodies are in the background. The girl seems adrift, crammed up in between these intensely sexual hypostases, looking away from both, far beyond the borders of the image itself. The viewer is thus invited to speculate on the nature of sexuality as an animalistic drive, which symbolically erases the heads of the two lovers in the background and entangles their bodies in an articulated spasm, with the woman almost devouring the man. This image discusses the monstrous aspect of female sexuality, as the cultural projection of the collective fears that, through its constitutive anomalies and ambiguities, the female body incites. In this respect, 
Rosi Braidotti notes that:

if we define the monster as a bodily entity that is anomalous and deviant vis-à-vis the norm, then we can argue that the female body shares with the monster the privilege of bringing out a unique blend of fascination and horror. This logic of attraction and repulsion is 71 extremely significant; psychoanalytic theory takes it as the fundamental structure of the mechanism of desire and, as such, of the constitution of the neurotic symptom: the spasm of the hysteric turns to nausea, displacing itself from its object. (Braidotti in Writing on the Body 65)

Mann's Lisa and the Dog captures the emerging female sexuality caught in between attraction and repulsion, fascination and horror, indifference and desire, here and there.

In Leah and her Father, Julie, John and Dollhouse and Teresa and Tattooed Man, Mann chooses to place her teenagers in sharp contrast with their grown-up male guardians. In all these instances there is a marked element of seemingly affectionless possession and firm domination in the relationship between the men and the girls. Domination is reinforced in the way arms reach out as if to mark territorial boundaries, in the way bodies are positioned and light falls on them, but it is also subverted by the fact that it is the girls who look straight into the camera, while the men all look away. As Robert Jensen argues in a study on the ideology of pornography,

domination and submission are made sexual, sometimes in explicit representations of rape and violence against women, but always in the objectification and commodification of women and their sexuality. (Jensen 2)

There is an interesting circulation of power in these three photos, a compelling commentary on the nature of gender roles and relationships, a powerful subversion of traditional models and patterns. The teenage girl is once again caught in-between predestination and freedom, between conforming to the rule of the Father and exiting the binary logic. As Nicholas Mirzoeff argues,

The coherence of the represented body is, however, constantly undermined 
by the very incompleteness these images seek to overcome. The body is the object of whose materiality we are most certain, but the undefinable potential of that inevitably incomplete materiality remains a constant source of unease. (Mirzoeff 19)

\section{Conclusions}

The audacity of Sally Mann's photographic essay is certainly undisputable. Perhaps, today, improbable. In a decade when Western culture was actively reconfiguring categories, re-establishing boundaries and re-evaluating taboos, At Twelve: Portraits of Young Women took a step further. It illustrated, avant la lettre, the dilemma that Mirzoeff presented in the introduction to his Bodyscape:

The body is involved in struggles that are political but are also inescapably issues of representation. How can the body be shown? Whose body should be shown? What corporal practices are 'normal', hence fit to be seen? (Mirzoeff 6)

It rewrote female adolescence as a place of choices rather than chances, a place of infinite possibilities rather than well-defined pathways. Moreover, it heavily subverted the very notion of boundary or category, as Mann's protagonists are systematically hovering in-between. Their ambiguity is their defining trait. And it is used to make powerful statements on the nature and force of visual representation, as well as on the consecrated clichés of Western culture. Mann's Lolitas are outrageous and kind, childish and sensual, provocative and contained, fierce and vulnerable. Her photography is an audaciously true diary of universal girlhood, of womanhood on the brink of becoming, of the hopes and fears, certainties and uncertainties of emerging identities.

\section{Works Cited}

Braidotti, Rosi."Mothers, Monsters and Machines" in Writing on the Body, eds. Katie Conboy, Nadia Medina, Sarah Stanbury. Columbia University Press, 1997: 59-80. Print.

Currie, Mark. Postmodern Narrative Theory. London: Macmillan Press Ltd, 1998. Foucault, Michel. The Order of Things. New York, Vintage, 1994. Print. 
Freud, Sigmund. Collected Papers vol II. transl. by Joan Riviere. New York: Basic Books, 1959. Print.

---Totem and Taboo, transl. by James Strachey, London: Routledge, 2001. Print.

Gatens, Moira. Imaginary Bodies: Ethics, Power and Corporeality. London, Routledge, 1996. Print.

Harari, Yuval Noah. Homo Deus. New York, Harper, 2017. Print.

Irigaray, Lucy. This Sex Which is Not One. Transl. by Catherine Potter. Cornell University Press, 1985. Print.

Jensen, Robert. "Pornographic Dodges and Distortions" in Pornography: The Production and Consumption of Inequality, London: Routledge, 1998: 1-9.

Mirzoeff, Nicholas. Bodyscape. Second Edition, Taylor and Francis e-Library, 2005.

Robinson, Sally. Engendering the Subject. University of New York Press, 1991. 